Cite this: Phys. Chem. Chem. Phys., 2011, 13, 19393-19400

\title{
Structures and vibrational spectroscopy of partially reduced gas-phase cerium oxide clusters $\dagger$
}

\author{
Asbjörn M. Burow ${ }^{a}{ }^{\text {Torsten Wende }}{ }^{b}$ Marek Sierka, ${ }^{* a}$ Radosław Włodarczyk ${ }^{a}$

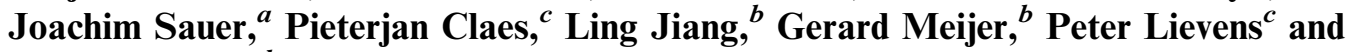 \\ Knut R. Asmis $* b$
}

Received 29th June 2011, Accepted 23rd August 2011

DOI: $10.1039 / \mathrm{c1cp22129a}$

This work demonstrates that the most stable structures of even small gas-phase aggregates of cerium oxide with $2-5$ cerium atoms show structural motifs reminiscent of the bulk ceria. This is different from main group and transition metal oxide clusters, which often display structural features that are distinctly different from the bulk structure. The structures of $\mathrm{Ce}_{2} \mathrm{O}_{2}{ }^{+}, \mathrm{Ce}_{3} \mathrm{O}_{4}{ }^{+}$, and $\left(\mathrm{CeO}_{2}\right)_{m} \mathrm{CeO}^{+}$clusters $(m=0-4)$ are unambiguously determined by a combination of global structure optimizations at the density functional theory level and infrared vibrational predissociation spectroscopy of the cluster-rare gas atom complexes. The structures of $\mathrm{Ce}_{2} \mathrm{O}_{2}{ }^{+}$ and $\mathrm{Ce}_{2} \mathrm{O}_{3}{ }^{+}$exhibit a $\mathrm{Ce}-\mathrm{O}-\mathrm{Ce}-\mathrm{O}$ four-membered ring with characteristic absorptions between 430 and $680 \mathrm{~cm}^{-1}$. Larger clusters have common structural features containing fused $\mathrm{Ce}-\mathrm{O}-\mathrm{Ce}-\mathrm{O}$ four-membered rings which lead to intense absorption bands at around 500 and $650 \mathrm{~cm}^{-1}$. Clusters containing a terminal $\mathrm{Ce}=\mathrm{O}$ bond show a characteristic absorption band between 800 and $840 \mathrm{~cm}^{-1}$. For some cluster sizes multiple isomers are observed. Their individual infrared signatures are identified by tuning their relative population through the choice of $\mathrm{He}, \mathrm{Ne}$ or $\mathrm{Ar}$ messenger atoms. The present results allow us to benchmark different density functionals which yield different degrees of localization of unpaired electrons in $\mathrm{Ce} 4 \mathrm{f}$ states.

\section{Introduction}

Understanding how the structure and properties of a chemical compound change with its dimensionality, i.e., when passing from the three-dimensional bulk solid to two-dimensional thin films and to zero-dimensional nanosized clusters or small molecules, is of fundamental interest in physics and chemistry. Systems with reduced dimensionality can display unusual structural diversity even for metal oxides with inherently stable bulk structures. The prominent examples here are gas-phase aggregates of magnesium oxide. ${ }^{1}$ Similarly, aluminium oxide, $\mathrm{Al}_{2} \mathrm{O}_{3}$, as low-dimensional material in the form of thin films $\mathrm{s}^{2-4}$

\footnotetext{
a Institut für Chemie, Humboldt-Universität zu Berlin,

Unter den Linden 6, D-10099 Berlin, Germany.

E-mail:marek.sierka@chemie.hu-berlin.de

${ }^{b}$ Fritz-Haber-Institut der Max-Planck-Gesellschaft, Faradayweg 4-6,

D-14195 Berlin, Germany. E-mail: asmis@fhi-berlin.mpg.de

${ }^{c}$ Laboratory of Solid State Physics and Magnetism, Katholieke

Universiteit Leuven, Celestijnenlaan 200D, B-3001 Leuven, Belgium

$\dagger$ Electronic supplementary information (ESI) available: B3LYP optimized structures of cerium oxide clusters. Comparison between the experimental IRVPD spectrum of $\mathrm{CeO}_{2} \mathrm{CeO}^{+} \cdot \mathrm{Ne}$ and $\mathrm{CeO}_{2} \mathrm{CeO}^{+}$. $\mathrm{He}$. Simulated absorption spectra of $\left(\mathrm{CeO}_{2}\right)_{4} \mathrm{CeO}^{+}$for the functional BP-86. A high resolution electron energy loss spectrum of surface ceria from Stubenrauch et al. ${ }^{74}$ prepared for the comparison with the IRVPD spectrum of $\left(\mathrm{CeO}_{2}\right)_{4} \mathrm{CeO}^{+} \cdot \mathrm{Ne}$. Table of atomic distances and coordination numbers. See DOI: $10.1039 / \mathrm{c} 1 \mathrm{cp} 22129 \mathrm{a}$
}

and clusters ${ }^{5,6}$ exhibits new structural features that are not found in any of its known solid polymorphs. It is therefore not surprising that also small aggregates of transition metal oxides show unusual structural features. For example, both charged and neutral vanadium oxide clusters form polyhedral cages unknown in bulk $\mathrm{V}_{2} \mathrm{O}_{5} \cdot{ }^{78} \mathrm{~A}$ similar behavior was shown for bimetallic $\mathrm{V}-\mathrm{Ti}$ oxide anion clusters ${ }^{9}$ and neutral $\left(\mathrm{TiO}_{2}\right)_{m}$ clusters. ${ }^{10}$ For the latter even clusters of sizes $m=9-15$ show geometrical structures which do not correspond to any of the known $\mathrm{TiO}_{2}$ polymorphs. An overview on the vibrational spectroscopy of gas-phase metal oxide clusters and the assignment of structures compared with computational results is given by Asmis et al. ${ }^{11}$

The surprising finding of the present study is that the most stable isomers of small cerium oxide clusters with $2-5 \mathrm{Ce}$ atoms show structural elements typical of bulk $\mathrm{CeO}_{2}$. Global structure optimizations of the clusters with compositions $\mathrm{Ce}_{2} \mathrm{O}_{2}{ }^{+}, \mathrm{Ce}_{3} \mathrm{O}_{4}{ }^{+}$, and $\left(\mathrm{CeO}_{2}\right)_{m} \mathrm{CeO}^{+}(m=0-4)$ have been made employing density functional theory (DFT). Since DFT calculations are of limited accuracy the final structure assignment is achieved by comparing the infrared (IR) absorption spectra, calculated for the lowest energy isomers, with measured IR vibrational predissociation ${ }^{12}$ (IRVPD) spectra. Previously, this approach was applied to determine the structures of other metal oxide cluster cations, including vanadium, ${ }^{13,14}$ aluminium, ${ }^{5,6}$ 
magnesium, ${ }^{1}$ and mixed V-Ce ${ }^{15}$ oxide clusters. Compared to previous work on cerium oxide clusters ${ }^{16-29}$ there are two novel aspects within our study. First, the structures are computationally predicted using ab initio global structure optimizations. Second, vibrational spectra of mass-selected cluster cations are used to check the theoretical predictions and assign cluster structures on the basis of comparison of the experimental and simulated IR spectra.

So far IR matrix isolation ${ }^{16,17}$ and visible fluorescence ${ }^{18,19}$ spectroscopy have been used to characterize $\mathrm{CeO}$ and $\mathrm{CeO}_{2}$. Reactions of $\mathrm{CeO}_{2}{ }^{+}$with unsaturated hydrocarbons have been studied using mass spectrometry and discussed in conjunction with the electronic structure of $\mathrm{CeO}_{2}{ }^{+}$investigated by several ab initio methods. ${ }^{20}$ Similarly, the reactivity of $\left(\mathrm{CeO}_{2}\right)_{m}{ }^{+}$cerium oxide cations ${ }^{21}$ and cerium oxyhydroxide clusters $^{22}$ has been investigated by mass spectrometry and interpreted based on DFT calculations. For neutral $\left(\mathrm{CeO}_{2}\right)_{m}$ clusters different global minimum structures have been predicted computationally, depending on the exchange-correlation functional used. ${ }^{23,24}$ The properties of cerium oxide nanoparticles with octahedral shapes have been investigated using DFT and interionic potentials. ${ }^{25-27}$ These bulk-like structures are similar to those of ceria nanoparticles determined with $\mathrm{X}$-ray diffraction and transmission electron microscopy. ${ }^{28,29}$

The clusters studied in the present work are not fully oxidized, i.e., there are $\mathrm{Ce}$ atoms in the lower oxidation state than + IV. There is lively interest in partially reduced ceria ${ }^{30-35}$ which arises from a broad range of industrial applications ${ }^{36,37}$ including heterogeneous catalysis. ${ }^{30,38,39}$ Partially reduced ceria is formed when oxygen defects are created which leaves electrons in $\mathrm{Ce} 4 \mathrm{f}$ states. Experiments point to localized $\mathrm{Ce} 4 \mathrm{f}$ states $^{31,35}$ but DFT results strongly depend on the chosen exchange-correlation functional. The local density approximation (LDA) and the generalized gradient approximation (GGA) lead to delocalized occupied Ce $4 \mathrm{f}$ states. ${ }^{40}$ In contrast, calculations using hybrid functionals ${ }^{41-44}$ or the DFT $+\mathrm{U}$ scheme ${ }^{45-47}$ lead to localized $\mathrm{f}$ states on single Ce sites. For extended systems such as nanoparticles and surfaces, calculations using more demanding functionals, e.g., hybrid functionals are affordable only in exceptional cases. ${ }^{4-43}$ In contrast, cerium oxide clusters can be studied by a broad variety of functionals. ${ }^{20,21,23,24}$ Hence, the present joint computational-experimental study of clusters not only contributes to a better understanding of the properties and the electronic structure of partially reduced cerium oxide, but also serves as a benchmark for assessing the applicability of different computational methods to lanthanide oxide aggregates.

\section{Computational details}

DFT calculations are performed using the TuRBOMOLE program package. ${ }^{48,49}$ For the global structure optimizations the hybrid ab initio genetic algorithm ${ }^{50}$ is applied along with the TPSS exchange-correlation functional ${ }^{51}$ and triple-zeta valence plus polarization basis sets. ${ }^{52}$ The Stuttgart RSC Segmented basis set with polarization functions up to $g$ functions ${ }^{53}[10 \mathrm{~s}, 8 \mathrm{p}, 5 \mathrm{~d}, 4 \mathrm{f}, 1 \mathrm{~g}]$ and the relativistic small-core pseudopotential ${ }^{54}$ (28 electrons in the core) are adopted for cerium. In contrast to ref. 53 the cerium basis set contains only one polarization shell of $g$ functions with exponent 0.35 . Density fitting for the Coulomb term ${ }^{55,56}$ is applied to accelerate the self-consistent field (SCF) calculations. For all structures, final structure optimizations are performed using the B3LYP functional ${ }^{57,58}$ along with triple-zeta valence plus polarization basis sets ${ }^{59}$ on all atoms. The Ce basis set used for the global structure optimizations is augmented with two polarization shells of $g$ functions with exponents 0.84 and 2.25. In addition, for the $\left(\mathrm{CeO}_{2}\right)_{4} \mathrm{CeO}^{+}$cation, the GGA functional of Becke and Perdew ${ }^{60,61}$ (BP-86) and the TPSSh meta-GGA hybrid functional ${ }^{62}$ are applied. Structures are optimized until the energy change is smaller than $1 \times 10^{-7}$ Hartree and the Cartesian gradients are smaller than $1 \times 10^{-4}$ Hartree per Bohr. The SCF convergence criteria are $1 \times 10^{-7}$ Hartree for the energy and $1 \times 10^{-7}$ a.u. for the root-mean-square of the density. Frequency calculations are performed within the harmonic approximation using analytical second derivatives. ${ }^{63,64}$ IR spectra are simulated using unscaled vibrational frequencies and intensities calculated in the harmonic approximation from analytical derivatives of the dipole moment. The latter are convoluted using a Gaussian line shape function with a standard deviation of $4 \mathrm{~cm}^{-1}$. For the optimized structure of the $\mathrm{CeO}^{+} \cdot \mathrm{He}$ cation the rovibrational spectrum is simulated with the program PGOpher 7.0. ${ }^{65}$ The localization of occupied $\mathrm{Ce} f$ states is determined by spin density plots and, in addition, with a natural population analysis of the spin density. ${ }^{66}$

\section{Experiment}

IRVPD experiments are carried out using an ion trap/tandem mass spectrometer, ${ }^{67,68}$ temporarily installed at the Free Electron Laser for Infrared eXperiments (FELIX) facility ${ }^{69}$ at the FOM Institute Rijnhuizen (The Netherlands). Cerium oxide clusters are produced by laser ablation of a cerium target using a $10 \mathrm{~Hz}$ laser vaporization source. ${ }^{70}$ The plasma, containing the $\mathrm{Ce}$ atoms, is entrained in a pulse of $0.1 \% \mathrm{O}_{2}$ seeded in He carrier gas and expanded through a clustering channel. After passing through a $4 \mathrm{~mm}$ diameter skimmer the ions are collimated and translationally cooled in a buffer gas filled radio frequency (RF) decapole ion guide. Parent ions are mass-selected in a quadrupole mass filter, deflected by $90^{\circ}$ in an electrostatic quadrupole deflector, and focused into a cryogenically cooled $\mathrm{RF}$ ring electrode ion trap. To allow for continuous ion loading, ion thermalization, and ion-rare gas atom ( $\mathrm{He}, \mathrm{Ne}, \mathrm{Ar})$ complex formation, the trap is continuously filled with a buffer gas of pure $\mathrm{He}$, a mixture of $0.125 \% \mathrm{Ne}$, or $1 \% \mathrm{Ar}$ in $\mathrm{He}$ at ion trap temperatures of $15 \mathrm{~K}, 24 \mathrm{~K}$ and $55 \mathrm{~K}$, respectively. Rare gas tagged complexes are stabilized through threebody collisions. ${ }^{12}$ After filling the trap for $98 \mathrm{~ms}$, all ions are extracted from the ion trap and focused both temporally and spatially into the center of the extraction region of an orthogonally mounted linear time-of-flight (TOF) mass spectrometer. Here, the ion packet can be irradiated with the IR laser pulse prior to the application of high voltage pulses on the acceleration electrodes and the subsequent measurement of the TOF mass spectrum. IR spectra are obtained in the difference mode of operation (laser on-laser off) and recorded by monitoring all ion intensities simultaneously as the laser wavelength is scanned (50-70 measurements per wavelength step). FELIX is operated at a repetition rate of $5 \mathrm{~Hz}$ in the 
spectral range from $400-950 \mathrm{~cm}^{-1}$ with a bandwidth of $0.2 \%$ root mean square of the central wavelength and an average pulse energy of $10 \mathrm{~mJ}$. The photodissociation cross section $\sigma_{\text {IRVPD }}$ is determined from the relative abundances of the parent and photofragment ions, $I_{0}$ and $I(\nu)$, and the frequency dependent laser power $P(\nu)$ using $^{71}$

$$
\sigma_{\text {IRVPD }}=-\frac{\ln \left[I(\nu) / I_{0}\right]}{P(\nu)} .
$$

\section{Results}

$\mathrm{CeO}^{+}$

For the $\mathrm{CeO}^{+}$cation, a bond distance of $1.76 \AA$ and a stretching frequency of $911 \mathrm{~cm}^{-1}$ are calculated. The unchanged $\mathrm{Ce}=\mathrm{O}$ bond distance in the $\mathrm{CeO}^{+} \cdot \mathrm{He}$ complex and the energy of only $-4.9 \mathrm{~kJ} \mathrm{~mol}^{-1}$ for its formation

$$
\mathrm{He}+\mathrm{CeO}^{+} \rightarrow \mathrm{He} \cdot \mathrm{CeO}^{+}
$$

demonstrate the very weak bonding between the $\mathrm{He}$ atom and $\mathrm{CeO}^{+}$. Structure 1-1 of $\mathrm{CeO}^{+} \cdot \mathrm{He}$ shown in Fig. 1 belongs to the symmetry point group $C_{\mathrm{s}}$. The single unpaired electron in different Ce $\mathrm{f}$ states leads to almost degenerate ${ }^{2} A^{\prime}$ and ${ }^{2} A^{\prime \prime}$ electronic states. For both states, the calculated $\mathrm{Ce}=\mathrm{O}$ stretch frequency is redshifted by $1 \mathrm{~cm}^{-1}$ compared to the bare $\mathrm{CeO}^{+}$ cation and slightly higher than the experimental value of $891 \mathrm{~cm}^{-1}$. The nonlinear structure of $\mathrm{CeO}^{+} \cdot \mathrm{He}$ is confirmed by the profile of the $\mathrm{Ce}=\mathrm{O}$ stretch absorption band in the experimental IRVPD spectrum (Fig. 1), which shows three peaks that correspond to the $\mathrm{P}, \mathrm{Q}$, and $\mathrm{R}$ branches of an asymmetric rigid rotor. $^{72}$ In contrast, the simulated IR spectrum of linear $\mathrm{CeO}^{+} \cdot \mathrm{He}$ lacks the $\mathrm{Q}$ branch and shows only two peaks.

\section{$\mathrm{Ce}_{2} \mathrm{O}_{2}^{+}$}

The lowest energy structure $\mathbf{2 - 2}$ of the $\mathrm{Ce}_{2} \mathrm{O}_{2}{ }^{+}$cluster is a $D_{2 \mathrm{~h}}$-symmetric four-membered ring (Fig. 2). Three unpaired electrons in the $\mathrm{Ce} f$ states form a quadruplet spin state with both $\mathrm{Ce}$ atoms formally in the oxidation state +2.5 . Two unpaired electrons occupy the virtually degenerate $b_{1 u}$ and $b_{3 g}$ orbitals delocalized over both $\mathrm{Ce}$ atoms and composed of f functions. The third unpaired electron occupies the fully symmetric $a_{1 g}$ orbital lying $250 \mathrm{~kJ} \mathrm{~mol}^{-1}$ higher in energy.

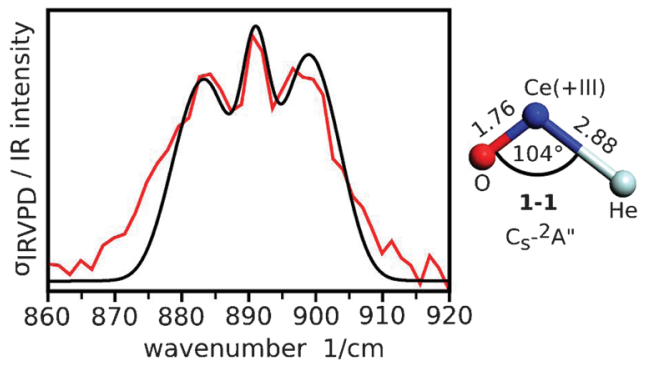

Fig. 1 Simulated IR absorption profile (black) and experimental IRVPD spectrum (red) of $\mathrm{CeO}^{+} \cdot \mathrm{He}$. The simulated spectrum includes rotational transitions within the rigid rotor approximation based on the calculated rotational constants $a=0.65, b=0.32$, and $c=0.22$. Rotational temperature of $100 \mathrm{~K}$ is assumed. The simulated spectrum is shifted by $-19 \mathrm{~cm}^{-1}$. Distances in $\AA$.
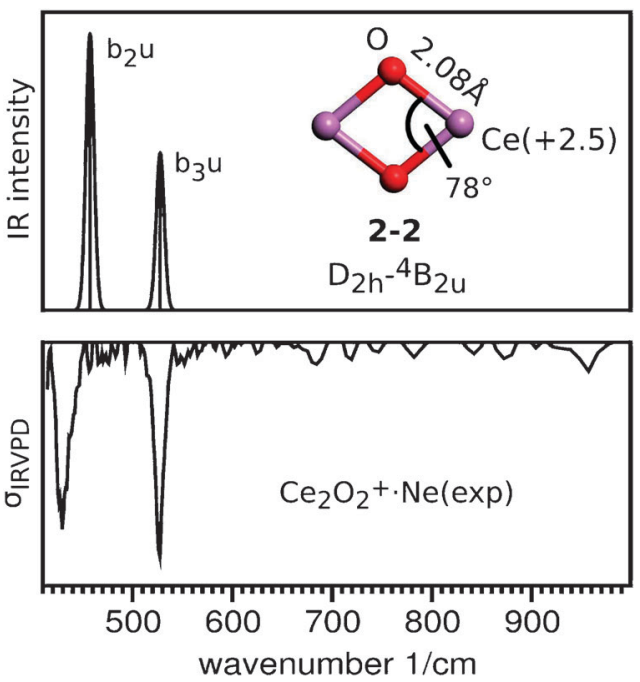

Fig. 2 Simulated IR absorption spectrum of structure 2-2 and experimental IRVPD spectrum of $\mathrm{Ce}_{2} \mathrm{O}_{2}{ }^{+} \cdot \mathrm{Ne}$. In the simulated spectrum, the absorption bands are labeled with the irreducible representations belonging to the vibrational normal modes.

This ${ }^{4} B_{2 u}$ ground state is $2 \mathrm{~kJ} \mathrm{~mol}^{-1}$ lower in energy than the highly spin contaminated $\left(\left\langle S^{2}\right\rangle=1.75\right) C_{2 \mathrm{v}}$-symmetric ${ }^{2} A_{1}$ state. Both states yield nearly identical vibrational spectra with six vibrational modes of which the five highest at 238, 322, 457, 528 , and $612 \mathrm{~cm}^{-1}$ are in-plane deformation modes of the ring. Due to the $D_{2 \mathrm{~h}}$ symmetry only the two in-plane modes at 457 and $528 \mathrm{~cm}^{-1}$ are IR active (Fig. 5). The IRVPD spectrum measured for $\mathrm{Ce}_{2} \mathrm{O}_{2}{ }^{+} \cdot \mathrm{Ne}$ exhibits the same pattern with two bands at 430 and $531 \mathrm{~cm}^{-1}$ (Fig. 2), confirming the structure assignment.

\section{$\mathrm{CeO}_{2} \mathrm{CeO}^{+}$}

Fig. 3 shows the two most stable structures of the $\mathrm{CeO}_{2} \mathrm{CeO}^{+}$ cation, 2-3a and 2-3b. The trigonal bi-pyramid with a $C_{3 \mathrm{v}}$ symmetry, 2-3b, is $7 \mathrm{~kJ} \mathrm{~mol}^{-1}$ higher in energy than the $C_{\mathrm{s}}$-symmetric structure 2-3a consisting of a four-membered ring with the additional terminal $\mathrm{O}$ atom linked to one cerium atom. In the ${ }^{2} A^{\prime}$ electronic state of 2-3a one unpaired electron occupies an $\mathrm{f}$ orbital on the twofold coordinated $\mathrm{Ce}$ atom. Structures 2-3a and 2-3b yield two different IR spectra (Fig. 4). While structure $\mathbf{2 - 3 b}$ is clearly not observed, the simulated spectrum of 2-3a agrees well with the experimental IRVPD spectrum of $\mathrm{CeO}_{2} \mathrm{CeO}^{+} \cdot \mathrm{Ne}$. In this spectrum, the three intense transitions in the range from 527 to $674 \mathrm{~cm}^{-1}$ are assigned to three in-plane modes of the ring (Fig. 5) and the signal at $840 \mathrm{~cm}^{-1}$ to the terminal $\mathrm{Ce}=\mathrm{O}$ stretching mode. A weak absorption $\left(1.4 \%\right.$ intensity with respect to the peak at $\left.684 \mathrm{~cm}^{-1}\right)$ is calculated for the fourth IR active in-plane mode at $254 \mathrm{~cm}^{-1}$. In addition, the experimental IRVPD spectrum shows several bands of small intensity at 506, 655, 690, 703, and $790 \mathrm{~cm}^{-1}$, which are enhanced by exchanging the $\mathrm{Ne}$ with a He messenger atom (see ESI $\dagger$ ).

\section{$\mathrm{Ce}_{3} \mathrm{O}_{4}{ }^{+}$}

The most stable isomer 3-4a shown in Fig. 3 contains three four-membered rings forming three faces of a rhombohedral 


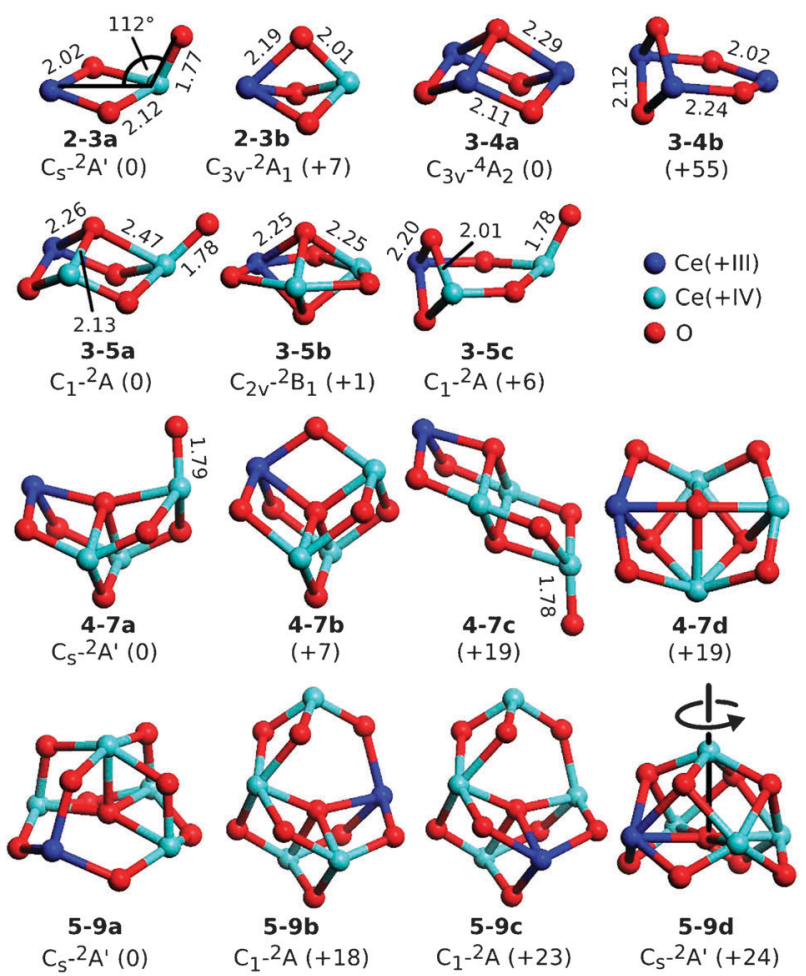

Fig. 3 B3LYP optimized structures, electronic states (if determined), relative total energies $\left(\mathrm{kJ} \mathrm{mol}^{-1}\right.$, in parentheses), and distances $(\AA)$ for clusters investigated in this work. The black line in structure 5-9d shows the rotation axis (see the text).

prism. This structure can be regarded as the $C_{3 \mathrm{v}}$-symmetric trigonal pyramid formed by the three $\mathrm{Ce}$ atoms capped with a threefold coordinated $\mathrm{O}$ atom on top. The remaining three twofold coordinated $\mathrm{O}$ atoms form the edges of the pyramidal base. Structure 3-4b, which is predicted to be $55 \mathrm{~kJ} \mathrm{~mol}^{-1}$ higher in energy, consists of a six-membered ring with one additional bridging $\mathrm{O}$ atom. In this structure one unpaired $\mathrm{f}$ electron is localized on one $\mathrm{Ce}$ atom and two unpaired $\mathrm{f}$ electrons are delocalized over the other two Ce atoms. This yields three $\mathrm{Ce}(+\mathrm{III})$ atoms. In 3-4a, three unpaired electrons in $\mathrm{Ce} f$ orbitals form the ${ }^{4} A_{2}$ electronic state in which all $\mathrm{Ce}$ atoms are formally reduced to $\mathrm{Ce}$ (+ III) (Fig. 3). One of the unpaired electrons occupies the fully symmetric forbital which is predicted to be $6 \mathrm{~kJ} \mathrm{~mol}^{-1}$ lower in energy than the doubly degenerate $f$ orbitals occupied by two unpaired electrons. The experimental IRVPD spectrum of $\mathrm{Ce}_{3} \mathrm{O}_{4}{ }^{+} \cdot \mathrm{Ne}$ shows four absorption bands at 413, 507, 536, and $633 \mathrm{~cm}^{-1}$ (Fig. 4). These transitions can be attributed to structure 3-4a. The two strong IR bands at 507 and $633 \mathrm{~cm}^{-1}$ result from two doubly degenerate normal modes and are illustrated in Fig. 5. Some bands of small intensity are observed at $563 \mathrm{~cm}^{-1}$ and in the range from 640 to $690 \mathrm{~cm}^{-1}$. These are tentatively assigned to isomer 3-4b.

\section{$\left(\mathrm{CeO}_{2}\right)_{2} \mathrm{CeO}^{+}$}

Fig. 3 shows the three most stable structures of $\left(\mathrm{CeO}_{2}\right)_{2} \mathrm{CeO}^{+}$. The energies of 3-5a and 3-5b are within $1 \mathrm{~kJ} \mathrm{~mol}^{-1}$ whereas the energy of 3-5c is $6 \mathrm{~kJ} \mathrm{~mol}^{-1}$ higher. Structures 3-5a and $\mathbf{3 - 5} \mathbf{c}$ can be derived from 3-4a and 3-4b, respectively, by adding a terminal $\mathrm{O}$ atom to one $\mathrm{Ce}$ site. $\mathbf{3 - 5 b}$ forms a distorted trigonal bi-pyramid with $C_{2 \mathrm{v}}$ symmetry. In each isomer, there is one unpaired electron in the $\mathrm{f}$ states localized at one $\mathrm{Ce}$ atom forming a doublet spin state. $\left(\mathrm{CeO}_{2}\right)_{2} \mathrm{CeO}^{+}$shows different IRVPD spectra depending on the messenger atom used (Ne and Ar, Fig. 4). The IRVPD spectrum of the Ne-tagged cluster exhibits a $\mathrm{Ce}=\mathrm{O}$ stretching band at $817 \mathrm{~cm}^{-1}$ which is not present in the spectrum of the Ar-tagged cluster. This indicates that the $\mathrm{Ne}$ atom preferentially binds to a structure containing a $\mathrm{Ce}=\mathrm{O}$ moiety whereas the $\mathrm{Ar}$ atom stabilizes a structure without it. Comparison of the experimental to the simulated IR spectra (Fig. 4) confirms that two isomers, 3-5a and 3-5b, are probed experimentally. The contribution of each isomer can be identified by changing the messenger atom which effectively tunes the relative isomer population.

\section{$\left(\mathrm{CeO}_{2}\right)_{3} \mathrm{CeO}^{+}$}

Fig. 3 shows the four most stable structures found for $\left(\mathrm{CeO}_{2}\right)_{3} \mathrm{CeO}^{+}$. The isomers $\mathbf{4 - 7 b}$ to $\mathbf{4 - 7 d}$ are located $+7,+19$, and $+19 \mathrm{~kJ} \mathrm{~mol}^{-1}$, respectively, above the global minimum structure 4-7a. Structure 4-7b consists of three pyramidal units 3-4a fused such that six twofold and one fourfold coordinated $\mathrm{O}$ atoms are formed whereas all $\mathrm{Ce}$ atoms are fourfold coordinated. The topology of 4-7a can be derived from 4-7b by disconnecting one twofold coordinated $\mathrm{O}$ atom from one $\mathrm{Ce}$ atom. In this way, a terminal $\mathrm{Ce}=\mathrm{O}$ bond and a threefold coordinated $\mathrm{Ce}$ atom are formed in the relaxed $C_{\mathrm{s}}$-symmetric structure 4-7a. 4-7c is composed of two pyramidal units which share one edge yielding two fourfold and two twofold coordinated $\mathrm{Ce}$ atoms. One twofold coordinated $\mathrm{Ce}$ atom is connected to the terminal $\mathrm{O}$ atom. $\mathbf{4 - 7} \mathbf{d}$ is formed by two bi-pyramidal units sharing one face. The most stable electronic state of all $\left(\mathrm{CeO}_{2}\right)_{3} \mathrm{CeO}^{+}$isomers is a doublet state with a single unpaired electron in a $\mathrm{Ce} f$ orbital. In all structures the $\mathrm{Ce}(+\mathrm{III})$ site coincides with the Ce atom of lowest coordination. The simulated IR absorption spectrum of structure 4-7a agrees with the experimental IRVPD spectrum of $\left(\mathrm{CeO}_{2}\right)_{3} \mathrm{CeO}^{+} \cdot \mathrm{Ne}$ (Fig. 4) except for the transition at $507 \mathrm{~cm}^{-1}$. For this transition, calculations yield a very small intensity while the experimental spectrum shows an intense peak. However, the best agreement between the experimental and the simulated spectra is found for 4-7a confirming the structure assignment.

\section{$\left(\mathrm{CeO}_{2}\right)_{4} \mathrm{CeO}^{+}$}

For $\left(\mathrm{CeO}_{2}\right)_{4} \mathrm{CeO}^{+}$, DFT calculations predict several low-energy structures. The assignment of these structures to the experimental spectrum is not straightforward and the results of a complementary set of exchange-correlation functionals are used to exclude structural candidates.

Fig. 3 shows the most stable structure types of $\left(\mathrm{CeO}_{2}\right)_{4} \mathrm{CeO}^{+}$. None of the structures have a terminal $\mathrm{O}$ atom. 5-9d consists of four fused bi-pyramidal units sharing two faces. The central $\mathrm{Ce}$ atom forms one of the pyramidal apices. This yields four twofold, four threefold, and one fivefold coordinated $\mathrm{O}$ atoms. Structure 5-9a can be derived from 5-9d by $45^{\circ}$ rotation of the threefold coordinated $\mathrm{O}$ atoms around the axis shown in Fig. 3. 5-9a is composed of four pyramidal units each of them sharing two faces. 5-9b and 5-9c have common structural 


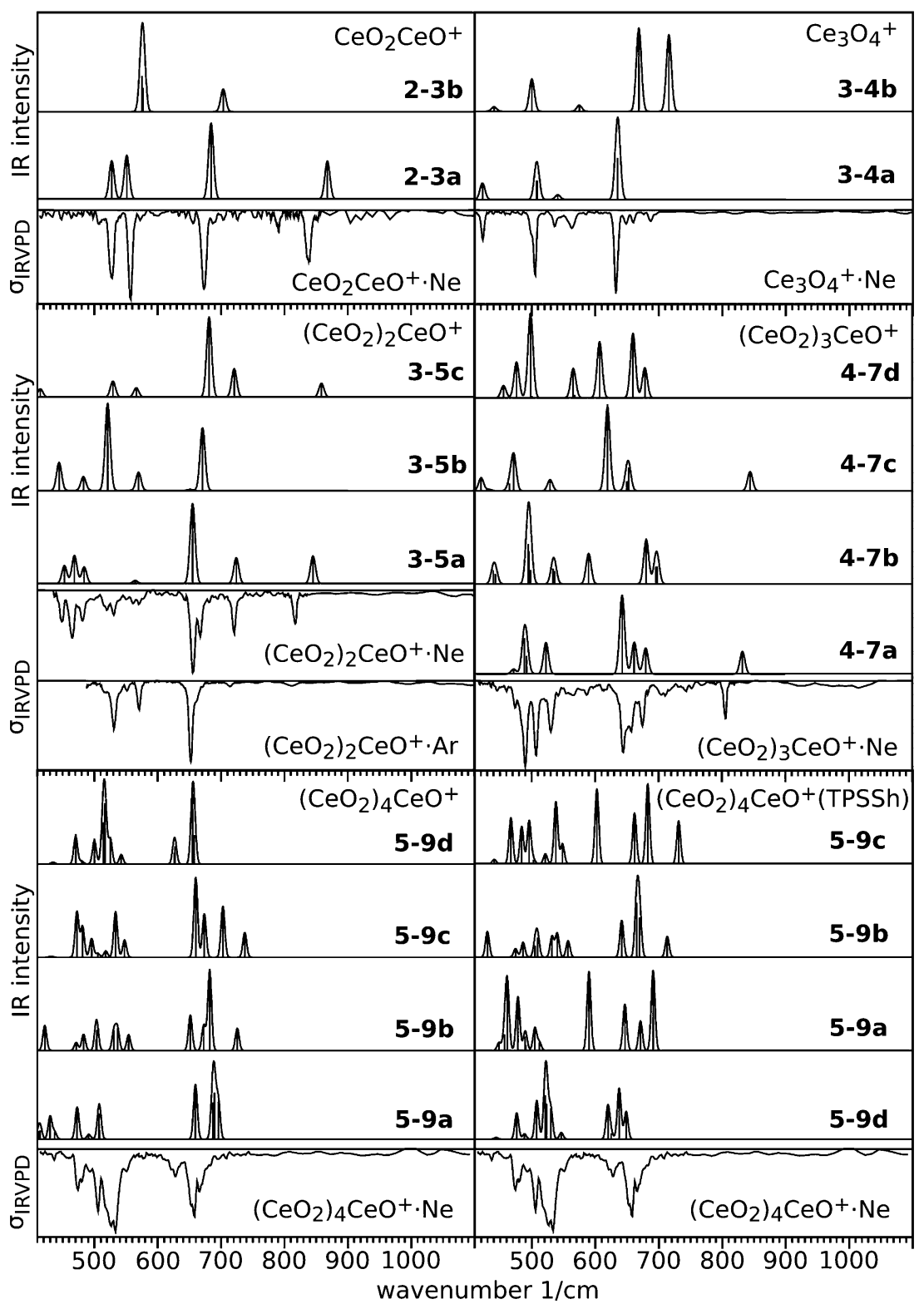

Fig. 4 Simulated IR absorption spectra (B3LYP level, for $\left(\mathrm{CeO}_{2}\right)_{4} \mathrm{CeO}^{+}$additionally TPSSh) of the clusters shown in Fig. 3 and experimental IRVPD spectra of the cluster-rare gas atom complexes.

features with 3-4b and 4-7a, i.e., the six-membered ring and the two pyramidal units sharing one face.

All structures have one unpaired electron in the Ce $f$ states. The degree of localization of the occupied $f$ state depends on the exchange-correlation functional used. Structure 5-9d is used to demonstrate this behavior for the functionals BP-86, B3LYP, and TPSSh. The localization of the occupied $f$ state is quantified by natural population analysis of the spin density. With BP-86, this $\mathrm{f}$ state contributes 0.27 a.u. to the spin density on four $\mathrm{Ce}$ atoms and 0.05 a.u. on the fifth $\mathrm{Ce}$ atom. For B3LYP and TPSSh the spin density resides almost completely on one $\mathrm{Ce}$ atom making it formally $\mathrm{Ce}(+\mathrm{III})$. For TPSSh the spin density on Ce(+IV) sites is 0.007 a.u. and one magnitude larger than for B3LYP (-0.0009 a.u.). Different spin localizations for the same structure type lead to different stable minima, e.g., 5-9b and 5-9c (Fig. 3).
Using the BP-86 functional, it was found that structure 5-9d is lowest in energy followed by $\mathbf{5 - 9 a}$ and 5-9b with 1 and $25 \mathrm{~kJ} \mathrm{~mol}^{-1}$, respectively. For B3LYP, the most stable structure is 5-9a while 5-9b, 5-9c, and 5-9d are higher by 18 , 23 , and $24 \mathrm{~kJ} \mathrm{~mol}^{-1}$, respectively. Employing the TPSSh functional, structure 5-9d is obtained as the global minimum while 5-9a is $40 \mathrm{~kJ} \mathrm{~mol}^{-1}$ higher in energy. The " $\mathrm{Ce}(+\mathrm{III})$ isomers" 5-9b and 5-9c are 61 and $68 \mathrm{~kJ} \mathrm{~mol}^{-1}$ higher in energy, respectively.

Only the IR absorption spectra of 5-9d obtained with the B3LYP and TPSSh functionals are in good agreement with the IRVPD spectrum of the $\left(\mathrm{CeO}_{2}\right)_{4} \mathrm{CeO}^{+}$. Ne complex (Fig. 4). Hence, structure 5-9d is attributed to the experimental spectrum. The simulated spectra using the functional BP- 86 do not show such an agreement for any of the structures (see ESI $\dagger$ ). 


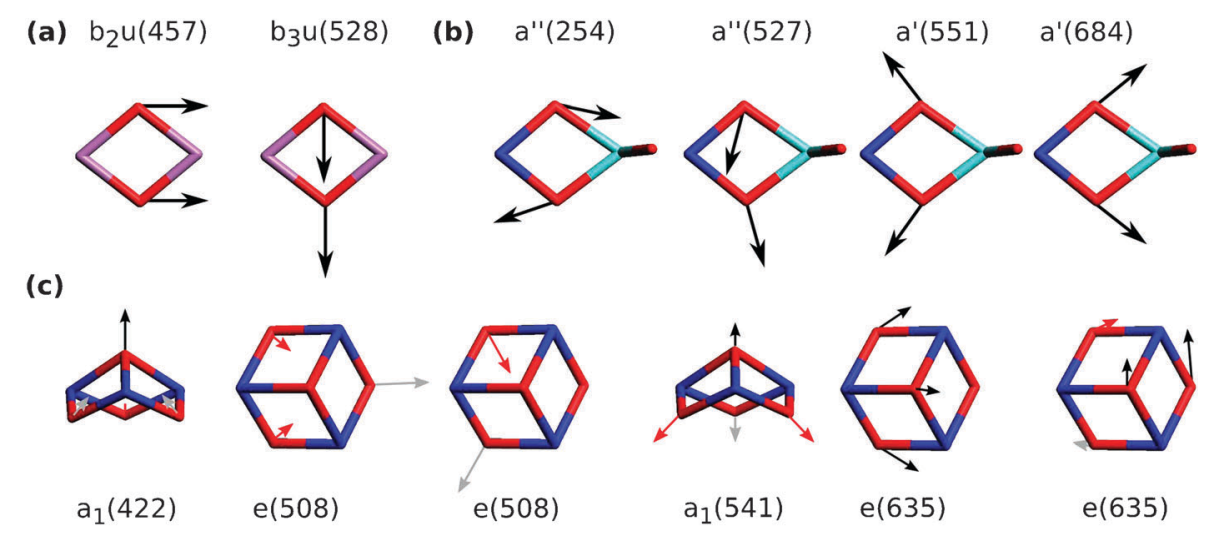

Fig. 5 IR active vibrational in-plane normal modes of (a) structure 2-2 and (b) structure 2-3a and (c) selected vibrational normal modes of structure 3-4a. Irreducible representations and harmonic frequencies $\left(\mathrm{cm}^{-1}\right.$, in parentheses). Black arrows: motions in the drawing plane; red and gray arrows: upward and downward motions, respectively.

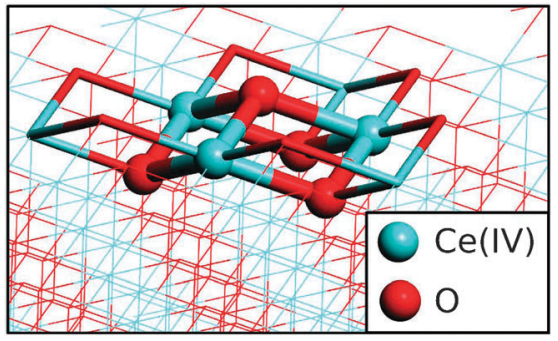

Fig. 6 Oxygen-terminated (111) surface with the highlighted pyramidal $\mathrm{Ce}_{3} \mathrm{O}_{4}$ unit.

\section{Discussion}

The cerium oxide clusters investigated in the present work reveal structural features closely related to bulk ceria. The most stable structures of $\mathrm{Ce}_{2} \mathrm{O}_{2}{ }^{+}$and $\mathrm{Ce}_{2} \mathrm{O}_{3}{ }^{+}$contain a $\mathrm{Ce}-\mathrm{O}-\mathrm{Ce}-\mathrm{O}$ four-membered ring which is also part of the bulk structure ( $c f$. Fig. 6). This ring structure is similar to the $\mathrm{V}_{2} \mathrm{O}_{2}{ }^{+}$and $\mathrm{V}_{2} \mathrm{O}_{3}{ }^{+}$divanadium clusters which have been investigated before. ${ }^{13}$ The calculated spectral signature of the $D_{2 \mathrm{~h}}$-symmetric four-membered $\mathrm{Ce}_{2} \mathrm{O}_{2}{ }^{+}$ring consists of two absorption bands at 457 and $528 \mathrm{~cm}^{-1}$ (Fig. 2) assigned to the IR active in-plane deformation modes of the ring (Fig. 5). The $\mathrm{V}_{2} \mathrm{O}_{2}{ }^{+}$cation shows an additional IR active in-plane vibration due to a lower symmetry $\left(C_{\mathrm{s}}\right.$ or $\left.C_{2 \mathrm{v}}\right)$. The four-membered ring of 2-3a shows four IR active in-plane modes (Fig. 5). Three of them are assigned to the three absorption bands from 527 to $674 \mathrm{~cm}^{-1}$ in the IRVPD spectrum (Fig. 4). This pattern is also observed for the $\mathrm{V}_{2} \mathrm{O}_{3}{ }^{+}$cation in the region from 650 to $1050 \mathrm{~cm}^{-1}$. Similarly, the work on zirconium oxide clusters ${ }^{73}$ gave experimental evidence for four-membered rings as a structural motif of small metal oxide clusters. The clusters with more than two Ce atoms, e.g., 3-4a are composed of pyramidal units leading to strong IR signals at around 500 and $650 \mathrm{~cm}^{-1}$. The structural motif of 3-4a is also found in the oxygen-terminated (111) ceria surface (Fig. 6). The high resolution electron energy loss spectrum of this surface measured by Stubenrauch et al. ${ }^{74}$ shows only a single broad $\left(\sim 100 \mathrm{~cm}^{-1}\right)$ band at $500 \mathrm{~cm}^{-1}$ (see also ESI $\dagger$ ). This suggests that the absorption features at around $650 \mathrm{~cm}^{-1}$ mentioned above should be further redshifted in larger cerium oxide clusters.
The computational results show that in all clusters with a terminal $\mathrm{O}$ atom, this is always connected to a $\mathrm{Ce}$ atom of the oxidation state $+\mathrm{IV}$. This $\mathrm{Ce}$ atom and the terminal $\mathrm{O}$ atom form the shortest bond in the clusters (1.76-1.79 $\AA$, see ESI $\dagger$ ) with stretching frequencies between 800 and $840 \mathrm{~cm}^{-1}$ in the IRVPD spectra of 2-3a, 3-5a, 4-7a. The Ce(+ III) atoms in the clusters have larger $\mathrm{Ce}-\mathrm{O}$ distances $(2.02-2.36 \AA)$ than $\mathrm{Ce}(+\mathrm{IV})$ atoms which do not have bonds to the terminal $\mathrm{O}$ atoms $(2.01-2.23 \AA)$.

The electronic structure of partially reduced cerium oxide clusters obtained with the B3LYP and TPSSh hybrid functionals displays $\mathrm{Ce}$ atoms in oxidation states + III and + IV. The Ce(+ III) atoms are formed by occupation of the $4 \mathrm{f}$ states. At the B3LYP level these $f$ states are localized on single $\mathrm{Ce}$ atoms except for the clusters $\mathbf{2 - 2}, \mathbf{3 - 4 a}$, and $\mathbf{3 - 4} \mathbf{b}$. In structure 2-2 this leads to two $\mathrm{Ce}(+2.5)$ atoms. In the $\left(\mathrm{CeO}_{2}\right)_{4} \mathrm{CeO}^{+}$ cluster, the occupied $\mathrm{Ce} 4 \mathrm{f}$ states delocalize if the electronic structure is calculated with the BP-86 functional. Similar results are obtained for reduced ceria surfaces. ${ }^{40,43,45,46}$

A previous DFT $+\mathrm{U}$ study predicted the structures for neutral cerium oxide clusters. ${ }^{23}$ Some of them have the same composition as the ones investigated in the present work, i.e., $\left(\mathrm{CeO}_{2}\right)_{m} \mathrm{CeO}^{+}(m=1-3)$. The predicted structures of these neutral clusters are similar to the cationic structures presented in Fig. 3 but the most stable structures of the neutral clusters are different from the global minimum structures of the cations.

Chen et $a l .{ }^{24}$ performed a global minimum search for $\left(\mathrm{CeO}_{2}\right)_{5}$ using the fast inertial relaxation engine ${ }^{75}$ combined with simulated annealing on the PW91 potential energy surface. The $\left(\mathrm{CeO}_{2}\right)_{5}$ structure found is similar to the structure one would obtain if an additional $\mathrm{O}$ atom were inserted between two fourfold coordinated $\mathrm{Ce}$ atoms in isomer $\mathbf{5 - 9} \mathbf{a}$ of $\left(\mathrm{CeO}_{2}\right)_{4} \mathrm{CeO}^{+}$.

\section{Summary and conclusions}

The structures of the partially reduced gas-phase cerium oxide clusters with compositions $\mathrm{Ce}_{2} \mathrm{O}_{2}{ }^{+}, \mathrm{Ce}_{3} \mathrm{O}_{4}{ }^{+}$, and $\left(\mathrm{CeO}_{2}\right)_{m} \mathrm{CeO}^{+}$ $(m=0-4)$ are identified. Given the different predictions of different density functionals, we conclude that both theory and experiment are required for determining the lowest energy isomers of these clusters. The dicerium clusters form $\mathrm{Ce}-\mathrm{O}-\mathrm{Ce}-\mathrm{O}$ fourmembered rings typical for small transition metal oxide clusters. 
The clusters containing more than two Ce atoms are composed of "pyramidal" structural subunits leading to intense IR signals at around 500 and $650 \mathrm{~cm}^{-1}$. Absorption signals in the range from 800 to $840 \mathrm{~cm}^{-1}$ are fingerprints for terminal $\mathrm{Ce}=\mathrm{O}$ in all clusters. Whereas smaller gas-phase metal oxide clusters often have quite different structural features and properties compared to the corresponding bulk metal oxides ${ }^{1,5,7,8,10}$ we find the cerium oxide gas phase clusters to represent "slightly modified" fragments of bulk ceria. This key finding supports the use of gas-phase cerium oxide clusters in mass spectrometric reactions, e.g., ref. 21 as models for catalytic processes on ceria surfaces.

\section{Acknowledgements}

We would like to thank the Stichting voor Fundamenteel Onderzoek der Materie (FOM) for beam time at FELIX and the FELIX-staff for support and assistance. This research is funded by the German Research Foundation (Center of Collaborative Research 546), by the Fund for Scientific Research-Flanders (FWO), the K.U. Leuven Research Council (BOF, GOA and IDO programs), and the European Community's Seventh Framework Programme (FP7/2007-2013) grant no. 226716. L. Jiang thanks the Alexander von Humboldt Foundation for a post-doctoral scholarship, and P. Claes and A. Burow thank the Agency for Innovation by Science and Technology in Flanders (IWT) and the Stiftung StipendienFonds des Verbandes der Chemischen Industrie, respectively, for a doctoral scholarship.

\section{References}

1 K. Kwapien, M. Sierka, J. Döbler, J. Sauer, M. Haertelt, A. Fielicke and G. Meijer, Angew. Chem., Int. Ed., 2011, 50, 1716-1719.

2 G. Kresse, M. Schmid, E. Napetschnig, M. Shishkin, L. Köhler and P. Varga, Science, 2005, 308, 1440-1442.

3 M. Schmid, M. Shishkin, G. Kresse, E. Napetschnig, P. Varga, M. Kulawik, N. Nilius, H.-P. Rust and H.-J. Freund, Phys. Rev. Lett., 2006, 97, 046101.

4 Q.-H. Wu, A. Fortunelli and G. Granozzi, Int. Rev. Phys. Chem., 2009, 28, 517-576.

5 M. Sierka, J. Döbler, J. Sauer, G. Santambrogio, M. Brümmer, L. Wöste, E. Janssens, G. Meijer and K. R. Asmis, Angew. Chem., Int. Ed., 2007, 46, 3372-3375.

6 G. Santambrogio, E. Janssens, S. Li, T. Siebert, G. Meijer, K. R. Asmis, J. Döbler, M. Sierka and J. Sauer, J. Am. Chem. Soc., 2008, 130, 15143-15149.

7 S. F. Vyboishchikov and J. Sauer, J. Phys. Chem. A, 2001, 105, 8588-8598.

8 K. R. Asmis, G. Santambrogio, M. Brümmer and J. Sauer, Angew. Chem., 2005, 117, 3182-3185.

9 E. Janssens, G. Santambrogio, M. Brümmer, L. Wöste, P. Lievens, J. Sauer, G. Meijer and K. R. Asmis, Phys. Rev. Lett., 2006, 96, 233401.

10 S. Hamad, C. R. A. Catlow, S. M. W. S. Lago and J. A. Mejías, J. Phys. Chem. B, 2005, 109, 15741-15748.

11 K. R. Asmis, A. Fielicke, G. von Helden and G. Meijer, Chem. Phys. Solid Surf., 2007, 12, 327-375.

12 M. Brümmer, C. Kaposta, G. Santambrogio and K. R. Asmis, J. Chem. Phys., 2003, 119, 12700-12703.

13 K. R. Asmis, G. Meijer, M. Brümmer, C. Kaposta, G. Santambrogio, L. Wöste and J. Sauer, J. Chem. Phys., 2004, 120, 6461-6470.

14 T. Wende, J. Döbler, L. Jiang, P. Claes, E. Janssens, P. Lievens, G. Meijer, K. R. Asmis and J. Sauer, Int. J. Mass Spectrom., 2010, 297, 102-106.

15 L. Jiang, T. Wende, P. Claes, S. Bhattacharyya, M. Sierka, G. Meijer, P. Lievens, J. Sauer and K. R. Asmis, J. Phys. Chem. A, 2011, DOI: $10.1021 /$ jp203276g.
16 S. D. Gabelnick, G. T. Reedy and M. G. Chasanov, J. Chem. Phys., 1974, 60, 1167-1171.

17 S. P. Willson and L. Andrews, J. Phys. Chem. A, 1999, 103, 3171-3183.

18 C. Linton, M. Dulick and R. W. Field, J. Mol. Spectrosc., 1979, 78, 428-436.

19 C. Linton, M. Dulick, R. W. Field, P. Carette and R. F. Barrow, J. Chem. Phys., 1981, 74, 189-191.

20 C. Heinemann, H. H. Cornehl, D. Schröder, M. Dolg and H. Schwarz, Inorg. Chem., 1996, 35, 2463-2475.

21 X.-N. Wu, Y.-X. Zhao, W. Xue, Z.-C. Wang, S.-G. He and X.-L. Ding, Phys. Chem. Chem. Phys., 2010, 12, 3984-3997.

22 F. Aubriet, J.-J. Gaumet, W. A. de Jong, G. S. Groenewold, A. K. Gianotto, M. E. McIlwain, M. J. Van Stipdonk and C. M. Leavitt, J. Phys. Chem. A, 2009, 113, 6239-6252.

23 S. F. Li, H. Lu, P. Li, Z. Yang and Z. X. Guo, J. Chem. Phys., 2008, 128, 164718.

24 C. Chen, H.-L. Chen, M.-H. Weng, S.-P. Ju, J.-G. Chang and C.-S. Chang, Chin. J. Catal., 2008, 29, 1117-1121.

25 C. Loschen, S. T. Bromley, K. M. Neyman and F. Illas, J. Phys. Chem. C, 2007, 111, 10142-10145.

26 C. Loschen, A. Migani, S. T. Bromley, F. Illas and K. M. Neyman, Phys. Chem. Chem. Phys., 2008, 10, 5730-5738.

27 A. Migani, K. M. Neyman, F. Illas and S. T. Bromley, J. Chem. Phys., 2009, 131, 064701.

28 Z. L. Wang and X. Feng, J. Phys. Chem. B, 2003, 107, 13563-13566.

29 F. Zhang, Q. Jin and S.-W. Chan, J. Appl. Phys., 2004, 95, 4319-4326.

30 A. Trovarelli, Catal. Rev. Sci. Eng., 1996, 38, 439-520.

31 F. Esch, S. Fabris, L. Zhou, T. Montini, C. Africh, P. Fornasiero, G. Comelli and R. Rosei, Science, 2005, 309, 752-755.

32 C. T. Campbell and C. H. F. Peden, Science, 2005, 309, 713-714

33 A. Pfau and K. D. Schierbaum, Surf. Sci., 1994, 321, 71-80.

34 D. R. Mullins, P. V. Radulovic and S. H. Overbury, Surf. Sci., 1999, 429, 186-198.

35 J. F. Jerratsch, X. Shao, N. Nilius, H.-J. Freund, C. Popa, M. V. Ganduglia-Pirovano, A. M. Burow and J. Sauer, Phys. Rev. Lett., 2011, 106, 246801.

36 C. Pijolat, G. Tournier and J. P. Viricelle, Sens. Actuators, B, 2009, $141,7-12$.

37 N. Izu, W. Shin, I. Matsubara and N. Murayama, Sens. Actuators, B, 2009, 139, 317-321.

38 R. J. Gorte, AlChE J., 2010, 56, 1126-1135.

39 W. Z. Zhu and S. C. Deevi, Mater. Sci. Eng., A, 2003, 362, 228-239.

40 Z. Yang, T. K. Woo, M. Baudin and K. Hermansson, J. Chem. Phys., 2004, 120, 7741-7749.

41 P. J. Hay, R. L. Martin, J. Uddin and G. E. Scuseria, J. Chem. Phys., 2006, 125, 034712.

42 J. L. F. Da Silva, M. V. Ganduglia-Pirovano, J. Sauer, V. Bayer and G. Kresse, Phys. Rev. B: Condens. Matter, 2007, 75, 045121.

43 M. V. Ganduglia-Pirovano, J. L. F. Da Silva and J. Sauer, Phys. Rev. Lett., 2009, 102, 026101.

44 J. Kullgren, C. W. M. Castleton, C. Müller, D. M. Ramo and K. Hermansson, J. Chem. Phys., 2010, 132, 054110.

45 S. Fabris, G. Vicario, G. Balducci, S. de Gironcoli and S. Baroni, J. Phys. Chem. B, 2005, 109, 22860-22867.

46 M. Nolan, J. E. Fearon and G. W. Watson, Solid State Ionics, 2006, 177, 3069-3074.

47 D. A. Andersson, S. I. Simak, B. Johansson, I. A. Abrikosov and N. V. Skorodumova, Phys. Rev. B: Condens. Matter, 2007, 75, 035109.

48 Turbomole, V6.2 2010, a development of University of Karlsruhe and Forschungszentrum Karlsruhe GmbH, 1989-2007, Turbomole $\mathrm{GmbH}$, since 2007; available from http://www.turbomole.com.

49 R. Ahlrichs, M. Bär, M. Häser, H. Horn and C. Kölmel, Chem. Phys. Lett., 1989, 162, 165-169.

50 M. Sierka, Prog. Surf. Sci., 2010, 85, 398-434.

51 J. Tao, J. P. Perdew, V. N. Staroverov and G. E. Scuseria, Phys. Rev. Lett., 2003, 91, 146401.

52 A. Schäfer, C. Huber and R. Ahlrichs, J. Chem. Phys., 1994, 100, $5829-5835$.

53 X. Cao and M. Dolg, J. Chem. Phys., 2001, 115, 7348-7355.

54 M. Dolg, H. Stoll and H. Preuss, J. Chem. Phys., 1989, 90, 1730-1734.

55 K. Eichkorn, O. Treutler, H. Öhm, M. Häser and R. Ahlrichs, Chem. Phys. Lett., 1995, 242, 652-660. 
56 K. Eichkorn, F. Weigend, O. Treutler and R. Ahlrichs, Theor. Chem. Acc., 1997, 97, 119-124.

57 A. D. Becke, J. Chem. Phys., 1993, 98, 5648-5652.

58 C. Lee, W. Yang and R. G. Parr, Phys. Rev. B: Condens. Matter, 1988, 37, 785-789.

59 F. Weigend and R. Ahlrichs, Phys. Chem. Chem. Phys., 2005, 7, 3297-3305.

60 A. D. Becke, Phys. Rev. A, 1988, 38, 3098-3100.

61 J. P. Perdew, Phys. Rev. B: Condens. Matter, 1986, 34, 7406.

62 V. N. Staroverov, G. E. Scuseria, J. Tao and J. P. Perdew, J. Chem. Phys., 2003, 119, 12129-12137.

63 P. Deglmann, F. Furche and R. Ahlrichs, Chem. Phys. Lett., 2002, 362, 511-518.

64 P. Deglmann, K. May, F. Furche and R. Ahlrichs, Chem. Phys. Lett., 2004, 384, 103-107.

65 PGopher, a Program for Simulating Rotational Structure, C. M. Western, University of Bristol, http://pgopher.chm.bris.ac.uk.

66 A. E. Reed, R. B. Weinstock and F. Weinhold, J. Chem. Phys., $1985,83,735-746$.
67 D. J. Goebbert, G. Meijer and K. R. Asmis, AIP Conf. Proc., 2009, 1104, 22-29.

68 D. J. Goebbert, T. Wende, R. Bergmann, G. Meijer and K. R. Asmis, J. Phys. Chem. A, 2009, 113, 5874-5880.

69 D. Oepts, A. F. G. van der Meer and P. W. van Amersfoort, Infrared Phys. Technol., 1995, 36, 297-308.

70 W. Bouwen, P. Thoen, F. Vanhoutte, S. Bouckaert, F. Despa, H. Weidele, R. E. Silverans and P. Lievens, Rev. Sci. Instrum., $2000,71,54-58$.

71 J. Oomens, A. G. G. M. Tielens, B. G. Sartakov, G. von Helden and G. Meijer, Astrophys. J., 2003, 591, 968-985.

72 H. W. Kroto, Molecular Rotation Spectra, John Wiley \& Sons, 1975.

73 G. von Helden, A. Kirilyuk, D. van Heijnsbergen, B. Sartakov, M. A. Duncan and G. Meijer, Chem. Phys., 2000, 262, 31-39.

74 J. Stubenrauch, E. Brosha and J. M. Vohs, Catal. Today, 1996, 28, 431-441.

75 E. Bitzek, P. Koskinen, F. Gähler, M. Moseler and P. Gumbsch, Phys. Rev. Lett., 2006, 97, 170201. 